\title{
Epidural Hemorrhage
}

National Cancer Institute

\section{Source}

National Cancer Institute. Epidural Hemorrhage. NCI Thesaurus. Code C50555.

Intracranial hemorrhage into the epidural space. 